\title{
1 Developing a long-term high-resolution winter fog climatology over south Asia using satellite observations from 2002 to 2020
}

3

4

$5 \quad{ }^{a}$ School of Engineering, University of Petroleum and Energy Studies, Dehradun - 248007, India

$6 \quad{ }^{\mathrm{b}}$ Environmental Defense Fund, Washington, DC 20009, USA

$7 \quad *$ Corresponding author - rgautam@edf.org

8

11 Abstract

12 The vast Indo-Gangetic Plains (IGP) south of the Himalaya are subject to dense fog every year

13 during winter months (December-January), severely disrupting rail, air and public transport of

14 millions of people living in northern India, Pakistan, Nepal and Bangladesh. Air pollution

15 combined with high moisture availability in the shallow boundary layer, are important factors

16

17 significance and impacts on the public at-large, an in depth understanding of the long-term

18 spatial-temporal distribution of the south Asian fog, is presently not available in the literature.

19 We utilize infrared remote sensing techniques to develop a high-resolution $(\approx 1 \mathrm{~km} \mathrm{x} 1 \mathrm{~km})$ fog

20 detection climatology over the past two decades (2002 - 2020), using Aqua/MODIS satellite

21 observations. A dynamic brightness temperature difference threshold (involving $3.96 \mu \mathrm{m}$ and

$22 \quad 11.03 \mu \mathrm{m}$ bands) for nighttime fog detection is constructed based on systematic radiative transfer

23 simulations involving cloud effective radius, cloud top height, cloud optical depth and satellite 
24 viewing geometry. Our satellite-based fog detection is consistent with theoretical simulations of

25 fog characterization and is also found to be well-correlated with near-surface visibility

26 observations of dense fog $(r=0.87$, p-value $<<0.01)$. We also provide satellite-derived

27 nighttime estimates of fog/low-cloud effective radius which is in general agreement with the operational daytime MODIS cloud data product and limited in situ observations. In terms of fog

29 frequency, the IGP is relatively uniformly covered by widespread fog occurrences with the largest frequency found in the low-lying Terai region, bordering India and Nepal, which is also

31 consistently observed in our daytime fog detection results over the last two decades.

32 Additionally, the interannual variations in fog occurrences track closely with that of relative

33 humidity in the IGP, which is associated with shallow boundary layer conditions during winter-

34 time favoring the formation and persistence of fog. Overall, these long-term satellite-derived results present new high-resolution data and insights into the dense and often intense winter fog occurrences which routinely engulf the entire stretch of the Indo-Gangetic Plains and cause significant degradation to ground visibility in one of the world's most densely populated regions.

\section{Introduction}

41 in the northern region of south Asia, experiences widespread and persistent occurrences of dense

42 fog. The IGP spreads across a vast stretch of agriculturally fertile belt, encompassing major parts

43 of northern India, Pakistan, Nepal and Bangladesh, and is among the topmost densely-populated

44 regions worldwide. The winter fog disrupts day-to-day lives of hundreds of millions of people

45 residing in the IGP (Hameed et al., 2000; Ghude et al., 2017; Gautam and Singh, 2018; Saikawa 
et al., 2019). Severe spells of fog often reduce the near-surface visibility to less than 50-100

47 meters causing prolonged delays and cancellations in air and rail transportation, resulting in large socio-economic losses, and are even known to episodically trigger vehicular accidents (Hameed et al., 2000; Gautam et al., 2007; Jenamani, 2007; Ghude et al., 2017). In polluted environments, dense fog is also associated with significant air quality degradation making it a serious public health issue (Decesari et al., 2017; Li et al., 2016; Agarwal et al., 2017; Gupta and Elumalai, 2018), as well as impacts to agriculture (Zhang et al., 2014; Bhatta et al., 2016).

High winter-time air pollution over south Asia, in particular over the IGP, associated with anthropogenic emissions from urban, residential and industrial sources (Venkataraman et al., 2018), combined with availability of sufficient moisture in the shallow boundary layer, are some of the important factors causing the severity, persistence and widespread nature of fog over IGP (Pasricha et al., 2003; Jenamani, 2007; Pan et al., 2015; Gautam et al., 2014; Ghude et al., 2017; Dey, 2018). Owing to the importance of the winter fog in the south Asian atmospheric environment including its coupling with air pollution as well as the impacts on the denselypopulated region, the understanding and characterization of fog across the IGP is critical for the purposes of fog monitoring, forecasting and assessing linkages with weather and pollution. Surface meteorological observations provide valuable information about visibility and weather related parameters needed to characterize fog episodes but these data are confined to a few point locations in the IGP and the current representation of the characteristics of fog is limited with large gaps in the context of south Asia (Gautam et al., 2007; Jenamani, 2007; Ghude et al. 2017). In this study, we utilize daily high-resolution satellite observations acquired during the past two decades, along with inputs from surface meteorological observations as well as model and 
observation-based reanalysis datasets, to map and quantify the spatial and temporal distribution

69 of the dense fog cover over the IGP.

Research on fog detection using satellite remote sensing has been carried out mainly

71 using multi-spectral systems involving thermal infrared channels (Gultepe et al., 2007). Hunt

72 (1973) suggested that small droplets found in fog are associated with lower emissivity at $3.7 \mu \mathrm{m}$

73 than at $10.8 \mu \mathrm{m}$, while the emissivity at these two bands is roughly the same for larger droplets.

74 The difference in emissivity leads to significant contrast in brightness temperatures at the mid-

75 infrared and thermal infrared bands. Further studies (e.g. Eyre et al.,1984; Turner et al., 1986;

76 Lee et al., 1997; Ahn et al., 2003; Cermak and Bendix, 2007) applied similar approaches to

77 satellite monitoring of nighttime fog/low stratus with observations from the Advanced Very High

78 Resolution Radiometer (AVHRR), the Geostationary Operational Environmental Satellite

79 Imager (GOES-8+), Geostationary Meteorological Satellite (GMS-5) and the Spinning Enhanced

80 Visible and Infrared Imager (SEVIRI) onboard the Meteosat Second Generation (MSG) satellite.

81 In addition, satellite-based infrared measurements combined with microwave data has also been

82 demonstrated towards fog characterization especially for the detection of marine fog (Wilcox, 83 2017).

Over south Asia, there have been several efforts involving satellite remote sensing of fog using the brightness temperature difference method and retrievals of cloud microphysical

86 properties (Gautam et al., 2007; Chaurasia et al., 2011; Ahmed et al., 2015; Dey, 2018; Gautam

87 and Singh, 2018; Banerjee and Padmakumari, 2020). Despite recent efforts in detecting and 88 characterizing fog over the IGP, a long-term spatial-temporal climatology of fog especially for 89 the nighttime observations does not exist. Here, using 19 years of Moderate resolution Imaging 90 Spectroradiometer (MODIS) satellite observations from 2002 to 2020, we produce a high- 
91 resolution climatological distribution of fog covering the entire IGP at $\approx 1 \mathrm{~km} \times 1 \mathrm{~km}$ spatial

92 resolution. Our study focuses on the nighttime fog while also providing a long-term climatology

93 of daytime fog frequency using Terra/MODIS data. In addition, we estimate Cloud Effective

94 Radius (CER) for the winter-time fog/low-cloud cover and discuss its characteristics over the

95 IGP. This work is carried out using a series of systematic radiative transfer simulations involving

96 daily nighttime radiance observations from Aqua/MODIS at 1:30 am local-time from 2002 to

97 2020. We also discuss the year-to-year variability in fog during the last two decades based on our

98 satellite-derived results, in conjunction with analysis of meteorological variables to explain the

99 fog variability across the IGP.

100

101

102

103

104

105

106

107

108

109

110

111

112

113

\section{Datasets}

We used Level-1b nighttime radiance and Level-2 cloud retrievals from MODIS observations for December-January months during the 19-year period 2002 to 2020 . For nighttime fog detection, both the Level-1b data and cloud products retrieved from MODIS onboard Aqua are used over the IGP bounded by $70^{\circ} \mathrm{E}-95^{\circ} \mathrm{E}, 20^{\circ} \mathrm{N}-33^{\circ} \mathrm{N}$. The Aqua satellite follows a descending night track, crossing the equator at approximately 2100 UTC (01:30 am local time). The MODIS instrument has a swath width of $2330 \mathrm{~km}$ which covers the globe every 1-2 days and provides multispectral imagery in 36 discrete bands from $0.4 \mu \mathrm{m}$ to $14.4 \mu \mathrm{m}$. For the nighttime fog detection algorithm, we used the emissive channels - band $22(3.939 \mu \mathrm{m}-$ $3.989 \mu \mathrm{m})$ and $31(10.780 \mu \mathrm{m}-11.280 \mu \mathrm{m})$ at $\approx 1 \mathrm{~km} \mathrm{x} 1 \mathrm{~km}$ spatial resolution (at nadir). The emissive bands are given in radiances (in the units of $W / \mathrm{m}^{2} / \mu \mathrm{m} / \mathrm{sr}$ ), which were converted to equivalent black body temperature or the brightness temperature by using the Planck's law.

In addition to nighttime radiance data, we used Level-2 retrievals including Cloud Top Height $(\mathrm{CTH})$, representing the geopotential height at cloud top pressure level, which is derived 
114 using infrared channel radiances. Cloud microphysical and optical properties such as Cloud 115 Optical Thickness (COT) and CER, derived using visible radiances, were also used for daytime 116 fog characterization. This product include datasets at a spatial resolution of $1 \mathrm{~km}$ or $5 \mathrm{~km}$. The 117 CER retrieval is obtained via a dual-channel retrieval method with band $7(2.1 \mu \mathrm{m})$ combined 118 with any one of the following visible-near infrared channels, band $1(0.65 \mu \mathrm{m})$, band $2(0.86 \mu \mathrm{m})$

119 or band $5(1.2 \mu \mathrm{m})$. In this study, all Level-2 cloud retrievals are used from MODIS Collection 6 120 data product where only high confidence quality assured cloud optical properties data are 121 reported (Platnick et al., 2016). For characterizing the impact of sensor viewing geometry on fog 122 detection, we used the MODIS sensor zenith angle. In addition for comparative analysis of the 123 nighttime simulated CER, we used the daytime CER which is available at a spatial resolution of $124 \quad 1 \mathrm{~km}$.

We also used surface-based meteorological data for intercomparing with the outputs of 126 the satellite-based fog detection algorithm. Specifically, the winter-time fog frequency is 127 compared with the visibility data obtained from the National Climate Data Center (NCDC). The 128 near-surface visibility data is part of the Integrated Surface Data (ISD), which includes 129 worldwide weather observations from over 20,000 ground stations. We note here that the inter130 comparison should not be considered as an ideal evaluation between satellite and surface131 detected fog due to some inherent factors involving satellite-based fog detection such as orbital 132 gaps in satellite data as well as the presence of overlaying clouds in the mid-high troposphere, 133 affecting the MODIS retrievals of low-lying fog.

\section{Nighttime fog remote sensing}

135 We primarily discuss here the nighttime fog detection framework using MODIS observations 136 over the IGP. In addition, we leverage an existing approach for daytime fog detection and 
137 present the fog characterization for both day and nighttime. In this section, we discuss a 138 physically-consistent radiative transfer based approach to detect fog/low stratus cloud during 139 nighttime, for the period 2002-2020 and apply it to the entire IGP towards developing a long140 term spatial-temporal climatology. The algorithm uses a dynamic threshold based on Brightness 141 Temperature Difference (BTD) instead of using a static threshold discussed in some previous 142 studies over India (Chaurasia et al., 2011; Ahmed et al., 2015; Dey, 2018).

We used a bi-spectral difference method which utilizes contrasting responses to fog by

144 two channels in the thermal bands (e.g. Ahn et al., 2003). The MODIS band 31 in the thermal IR 145 range $(11.02 \mu \mathrm{m})$ with an emissivity close to one for the fog (Eyre et al., 1984; Dey, 2018), is 146 associated with a higher emissivity for fog than the shortwave infrared band $22(3.96 \mu m)$. Fig. 1 147 shows three cases of widespread fog over the IGP on 30 January 2014 (Fig. 1a), 11 December 1482016 (Fig. 1b) and 1 January 2018 (Fig. 1c). Corresponding to these three cases, Fig. 2 shows 149 characteristic variations in brightness temperature $\left(T_{b}\right)$, with the $T_{b}$ (band 31$)$ on 30 January 1502014 (Fig. 2a), 11 December 2016 (Fig. 2b) and 1 January 2018 (Fig. 2c) higher compared to $151 T_{b}$ (band 22) for the respective dates (Fig. 2d, 2e, 2f) from Aqua/MODIS observations at 1:30 152 am local-time. The enhanced positive values in the brightness temperature difference $\Delta T_{b}=$ $153 T_{b}$ (band 31$)-T_{b}$ (band 22) observed in Fig. $2 \mathrm{~g}, 2 \mathrm{~h}, 2 \mathrm{i}$ are evident across the IGP associated 154 with the fog $\left(>2 K \Delta T_{b}\right)$. This characteristic positive difference is largely associated with a 155 reduced brightness temperature signal for band 22, which is most pronounced for fog/low-level 156 stratus clouds with small droplets. to the increased emissivity at band 22. In cloud-free conditions, the difference is much smaller 159 and mainly due to variations in water vapour absorption between the two bands (e.g. Ellrod et al., 

179 function.

1995). Additionally, the BTD method is also able to effectively distinguish fog from snowcovered areas (such as the Himalayan snow and ice cover) during nighttime, where the differences in the two spectral channels are insignificant, since snow emits more efficiently at the $3.9 \mu \mathrm{m}$ channel than fog, similar to a clear surface or sea (Ahn et al., 2003).

In principle, positive $\Delta T_{b}$ values indicate the presence of fog/low-level clouds; whereas negative $\Delta T_{b}$ is typically associated with the presence of high clouds and $\Delta T_{b} \approx 0$ (or negligible difference) indicates cloud-free conditions (Eyre et al., 1984). The value of $\Delta T_{b}$ varies with differences in the characteristics of cloud droplets in the atmosphere. In addition, $\Delta T_{b}$ also varies as a function of satellite sensor zenith angle ( $\theta)$ (Cermak and Bendix, 2007). We also note here that $\Delta T_{b}$ can be sensitive to changes in cloud top height $\left(h_{c}\right)$, with infrared (IR) and shortwave IR brightness temperatures varying for clouds closer to ground vs. cloud fields that are elevated in the troposphere.

For characterizing the relationship between CER and the corresponding brightness temperature, we used a combined approach based on satellite data and theoretical simualtions using a radiative transfer model: Santa Barbara Disort Atmospheric Radiative Transfer (SBDART), which is based on a collection of sophisticated and reliable physical models, developed and widely used by the atmospheric science community over the past decades (Ricchiazzi et al., 1999). Here, we simulate nighttime radiance at the top of atmosphere (TOA), which were converted to their respective brightness temperature by inverting the Plank's 

radiance/brightness temperatures, the simulated $T_{b}$ values at $\theta=20^{\circ}$ for $3.96 \mu \mathrm{m}$ and $11.02 \mu \mathrm{m}$, 183 with respect to cloud effective radius are shown in Fig. 3. The Fig. 3a shows that at $11.02 \mu m$, 184 the $T_{b}$ is not sensitive to changes in CER (symbolized here as $r_{c}$ ), as brightness temperature 185 values are nearly constant across values of CER (the $T_{b}$ ranges between $281-282 \mathrm{~K}$ for $2 \leq$ $r_{c} \leq 40 \mu m$ ). At $3.96 \mu m$, the $T_{b}$ is highly sensitive to the changes in $r_{c}$. For smaller droplet radii

187 (<15 $\mu m$ ), $T_{b}$ increases significantly from $274 \mathrm{~K}$ to $280 \mathrm{~K}$, but for higher values of $r_{c}$ (from 15 $\mu m$ to $40 \mu \mathrm{m}$ ), the $T_{b}$ becomes largely insensitive (varying from $280 \mathrm{~K}$ to $281 \mathrm{~K}$ ) to changes in $189 r_{c}$. Fig. $3 b$ shows that the difference between $T_{b}$ at $11.02 \mu m$ and $3.96 \mu m$ yields greater positive 190 values for lower $r_{c}$, whereas for higher $r_{c}$, the absolute value of $\Delta T_{b}$ is very small compared to 191 that of $\Delta T_{b}$ at lower $r_{c}$. For instance, there is an order of magnitude difference in the $\Delta T_{b}$ values 192 between $r_{c}=2 \mu m$ and $r_{c}=20 \mu m$.

Previous studies have suggested that majority of fog/low stratus clouds are associated 194 with small cloud effective radius (e.g. $r_{c}<9 \mu m$ ) (Bendix et al., 2005; Gautam et al., 2007; 195 Ghude et al., 2017). The simulated $\Delta T_{b}$ corresponding to $r_{c}<9 \mu m$ were found to be larger than 2.5 K (Fig. 3b). A fixed $\Delta T_{b}$ threshold is presently being used by the Indian Meteorological 197 Department (e.g. Chaurasia et al., 2011; Dey, 2018) for fog detection over India. However, our sensitivity analysis of the brightness temperature (Fig. 3) with radiative transfer computations 199 shows that the $\Delta T_{b}$ threshold varies significantly as a function of the $\tau_{c}, h_{c}$ and $\theta$ along with the $200 r_{c}$, and therefore should not be considered as a constant value such as the fixed $2.5 \mathrm{~K}$ threshold 201 considered in previous studies (Chaurasia et al., 2011). properties and satellite viewing geometry through a number of systematic radiative transfer 
204 computations. Fig. 4a shows the variation in $T_{b}$ with $r_{c}\left(2 \leq r_{c} \leq 40 \mu m\right)$ and $\tau_{c}\left(\tau_{c}=5,10,20\right.$, $20530)$ at $3.96 \mu \mathrm{m}$ and $11.03 \mu \mathrm{m}$. The $T_{b}$ at smaller $\tau_{c}$ is greater than the $T_{b}$ at higher $\tau_{c}$ at both the 206 SWIR and IR channels, due to the attenuation of the nighttime radiance as the opacity of the 207 cloud increases. Fig. $4 \mathrm{~b}$ shows $T_{b}$ as a function of $r_{c}$ and $h_{c}$ with $2 \leq r_{c} \leq 40 \mu m$ and $h_{c}$ varying 208 from $1 \mathrm{~km}$ to $4 \mathrm{~km}$. The top of the fog layer at higher altitudes is cooler than at lower altitudes, 209 which is evident in the lower brightness temperature at $h_{c}=4 \mathrm{~km}$ than at $h_{c}=1 \mathrm{~km}$, for both $2103.96 \mu \mathrm{m}$ and $11.03 \mu \mathrm{m}$. There is also a small but non-negligible variation present in $\Delta T_{b}$ 211 corresponding to $h_{c}$ for $r_{c}<9 \mu m$ (Fig. 4e). In addition, we find that the $\Delta T_{b}$ is smaller than $2 \mathrm{~K}$ 212 for fog layers with higher cloud tops and low cloud optical depth (for $r_{c}>9 \mu m$ ), further 213 indicating that low $\Delta T_{b}$ is plausible with cloud layer at high altitudes and larger $r_{c}$. Finally, the 214 largest sensitivity is found for the satellite viewing geometry where Fig. 4c shows the variation 215 in the $T_{b}$ with $\theta\left(0^{\circ} \leq \theta \leq 60^{\circ}\right)$. The brightness temperature at both the channels, $3.96 \mu m$ and $21611.02 \mu \mathrm{m}$, especially at the shorter wavelength, drops significantly at larger $\theta$, where the 217 distance between the sensor and the fog/low-cloud feature is greater than that at smaller $\theta$. 218 Specifically, the emitted radiation from the surface-fog feature passes through a longer 219 atmospheric path at larger $\theta$, which leads the brightness temperature to be cooler, compared to 220 lower temperature at smaller $\theta$. There is a pronounced variation in $\Delta T_{b}$ with $\theta$; for example at 9 $221 \mu m$, the $\Delta T_{b}$ is $4.5 \mathrm{~K}$ at $\theta=40^{\circ}$, significantly larger than $\Delta T_{b}$ of $2.5 \mathrm{~K}$ at $\theta=20^{\circ}$ (Fig. $4 \mathrm{f}$ ).

222 Overall, constraining the detection of foggy/low-cloud features is dependent on several key 223 variables including cloud effective radius, cloud optical thickness, cloud top height and sensor 224 viewing geometry, as shown here in the systematic radiative transfer simulations, underscoring 225 the need for a dynamic threshold of $\Delta T_{b}$ towards enabling a robust fog detection framework. 
Next, we characterize the dynamic threshold towards fog detection in satellite

227 observations against physically-consistent radiative transfer (RT) simulations. Fig. 5a shows the

228 brightness temperatures at $3.96 \mu \mathrm{m}$ and $11.03 \mu \mathrm{m}$ computed as a function of $\theta$ for different 229 cloud top heights $\left(h_{c}=1 \mathrm{~km}\right.$ and $\left.h_{c}=2 \mathrm{~km}\right)$ for $r_{c}=9 \mu \mathrm{m}$. As noted earlier, the $T_{b}$ at $h_{c}=$

$2302 \mathrm{~km}$ is lower than at $h_{c}=1 \mathrm{~km}$, with the $T_{b}$ decreasing at larger $\theta$ (particularly after sensor

231 zenith angle of $40^{\circ}$ ) for both the channels. Consequently, the $\Delta T_{b}$ increases at larger $\theta$ (Fig. 5b)

232 for both the $h_{c}=1 \mathrm{~km}$ and $2 \mathrm{~km}$, and follows approximately a third order polynomial. We 233 extracted a $T_{b}$ profile during a nighttime fog-covered scene from MODIS observations on 30

234 January 2014 (Fig. 5c), to characterize the variations in $T_{b}$ as a function of $\theta$ (from $7^{\circ}$ to

$23562^{\circ}$ ) and demonstrate the satellite-derived dynamic threshold for fog detection. The observed $T_{b}$ 236 profile (Fig. 5c) shows a similar variation as compared to the RT simulations with steep decline 237 in $T_{b}$ for oblique viewing geometry $\left(\theta>40^{\circ}\right)$. Fig. 5d shows that the observed foggy pixels

238 along the transect (supplementary Fig. S1) are associated with systematically increasing $\Delta T_{b}$, 239 which are greater than the theoretical threshold. Overall, the consistency between satellite 240 observations and RT simulations reinforces the significance of the need for a dynamical 241 threshold for fog detection.

\section{4. Long-term winter fog climatology over south Asia (2002-2020)}

Using the aforementioned approach, we apply the nighttime detection algorithm to 244 process daily fog maps from 2002 to 2020 over the IGP during the winter months of December 245 and January. Fig. 6 shows spatial distribution of nighttime fog episodes covering majority of the 246 IGP for 30 January 2014, 11 December 2016 and 1 January 2018, using Aqua/MODIS

247 observations. The maps were created at $0.01^{\circ} \mathrm{x} 0.01^{\circ}$ spatial resolution (approximately $1 \mathrm{~km} \mathrm{x} 1$ 
$248 \mathrm{~km}$ resolution). We also provide here an estimation of the CER for fog-detected pixels (relevant

249 information is provided in supplementary material). In Fig. $6 \mathrm{~b}$ and 6c, the spatial distribution of

250 our nighttime estimated CER along with the operationally-retrieved daytime CER from

251 Terra/MODIS are shown for foggy pixels on 30 January 2014, 11 December 2016 and 1 January

252 2018, respectively. A large fraction of CER less than $9 \mu \mathrm{m}$ (as also shown in Fig. S2 in

253 supplementary material) suggest the effectiveness of the fog CER estimation during nighttime

254 where the distribution is generally found to be consistent with the daytime CER.

255 We then expanded the processing of daily nighttime fog detection to develop a long-term 256 climatological distribution over the IGP, for the 19-year period 2002-2020. Fig. 7a shows the 257 mean seasonal (December-January) fog frequency from 2002-03 to 2020-21. Across the IGP, 258 the mean fog frequency varies between 5-20 days, with about 20\% of the winter nighttime 259 observations associated with fog/low cloud cover. The largest occurrences of fog are found in the 260 vicinity of the Himalayan foothills along the bordering areas of India and Nepal (as indicated by 261 red shading in Fig. 7a). This observation of enhanced fog frequency is consistent with daytime 262 observations of increased fog occurrences in the IGP near the Himalayan foothill as previously 263 reported by Gautam et al. 2007, which represents the Terai region (or the lowland areas of 264 northern India and southern Nepal).

We also observe this enhanced fog pattern in the overlapping MODIS daytime 266 climatological distribution over the same time period from 2002-03 to 2020-21 using data from 267 Terra observations at $\sim 10: 30$ am local-time (Fig. 7b). The Terai region is widely known in the 268 northern regions of south Asia for its 'seet lahar' phenomena where long periods of cold 269 conditions with low temperatures and calm winds persisting during the winter period, promoting 
270 the persistence of fog conditions, together with frequent low-level temperature inversion and

271 high relative humidity (Gautam et al., 2007; Ghude et al., 2017; Saikawa et al., 2019).

For the purposes of intercomparison and validation of our nighttime detection framework,

273 we use surface visibility data over 9 stations, as shown in supplementary Table S1, spread across

274 the IGP, namely Amritsar, Bareilly, Gaya, Gorakhpur, Hissar, Indira Gandhi International (IGI)

275 airport, Lucknow, Patna, and Safdarjung. Fig. 8 shows a scatter plot between poor visibility

276 frequency (visibility $<250 \mathrm{~m}$ ) derived from the surface meteorological data and fog frequency

277 obtained from the nighttime satellite data analysis. The poor visibility frequency in a winter

278 season at each station is computed by taking sum of the number of days when visibility is $<250$

$279 \mathrm{~m}$ at 2:30 am local-time, out of the total number of days in December-January, i.e. 62. The 2:30

280 am time stamp in the surface observations was the closest to the nighttime Aqua observations at

$281 \sim 1: 30$ am local-time. For each ground station, the corresponding satellite-derived seasonal fog

282 frequency is computed as the sum of the fog-detected data averaged for $3 \times 3$ pixels

283 (approximately 9 sq. $\mathrm{km}$ area) centered over the ground meteorological station. The slope of the

284 regression line as indicated in Fig. 8 is 0.86 with a correlation coefficient of 0.87 ( $p$-value $<<$

285 0.01), suggesting that the frequency in satellite-detected closely follows a statistically significant

286 relationship with fog-laden poor visibility conditions observed at surface. The correlation

287 coefficient reduces to 0.84 ( $p$-value $<0.01)$, when the visibility criteria is relaxed to less than

$288500 \mathrm{~m}$, suggesting that the satellite-based detection is rather indicative of dense fog resulting in

289 enhanced degradation of surface visibility (as indicated by higher correlation at poor visibility

290 conditions of $<250 \mathrm{~m})$.

291 In addition, the intercomparison analysis suggests slightly reduced frequency in fog 292 occurrences in the satellite detection as compared to the surface visibility data. Our fog retrievals 
293 based on MODIS data can be limited by the mid-high level clouds in the troposphere overlaying

294 and obscuring the fog layer closer to the ground. Furthermore, the orbital gaps also narrowly

295 reduce the data availability from the MODIS observations contributing to a low bias in the fog

296 frequency retrieved using satellite data. That said, the present intercomparison should not be

297 strictly considered as validation since the surface visibility refers to horizontal visibility while

298 the satellite-derived results correspond to atmospheric column. Overall, the close association

299 between satellite and surface data enhance confidence in our methodology demonstrating the

300 robustness of a high-resolution satellite data record covering the entire IGP in space and time.

301 We also analyzed the interannual variations in satellite-derived fog frequency with

302 ground-observed poor visibility conditions associated with fog (visibility $<250 \mathrm{~m}$ ) averaged

303 over the 9 meteorological stations, and found a significantly high correlation of 0.93 ( $p$-value $<<$

304 0.01) (Fig. 9). The year-to-year variations in fog are found to be well correlated with monthly

305 mean Relative Humidity (RH) (correlation coefficient of 0.77 ; p-value $<0.05$ ), with generally

306 lower RH associated with lower fog occurrences and vice versa. It is well known that high RH

307 conditions prevailing in the shallow boundary layer in the winter months favor the formation fog

308 in the IGP (Gautam et al., 2007; Ghude et al., 2017).

309

310

311

312

313

314

315

\section{Summary}

In this study, we use 19 years of satellite observations to produce a high-resolution $(\approx 1$

km x $1 \mathrm{~km}$ ) climatology of winter fog over south Asia focusing on the Indo-Gangetic Plains, using nighttime and daytime MODIS observations for the period 2002-2020. The physical basis for nighttime fog detection lies in the characteristic differences in the infrared brightness temperature calculated for MODIS $3.96 \mu \mathrm{m}$ and $11.03 \mu \mathrm{m}$ bands, associated with the emissive properties of the two channels for fog droplets. We used a radiative transfer framework involving 
satellite radiances and existing retrievals of cloud properties to map and quantify fog detections.

317 Here, we specifically constructed a dynamical threshold for fog detection based on brightness

318 temperature differences as a function of various satellite and fog/low-cloud parameters including

319 viewing geometry, fog effective radius, fog vertical distribution and its optical thickness. In

320 addition to fog detection, we also characterize size of fog/low-cloud droplets in terms of their

321 effective radius which is found to be less than $9 \mu \mathrm{m}$ (mean=7.2 and standard deviation=1.1). To

322 evaluate the performance of satellite-based fog analysis, the remote sensing derived results were

323 intercompared with near-surface data of poor visibility ( $<250 \mathrm{~m}$ visibility) based on nine

324 meteorological observing sites across the IGP.

Our results indicate a high correlation between the disparate satellite and ground-based approaches, which were also supported by a close interannual relationship between relative

327 humidity and fog occurrences over the last two decades, and further help shed light into the meteorological underpinnings of fog variability over the vast IGP. In addition, we processed the daytime fog climatology over the past two decades using thresholding approaches on a combination of cloud property retrievals from Terra/MODIS data. The nighttime and daytime analysis show similar spatial patterns and magnitudes of fog frequency across regions of

332 northern India, Pakistan, Nepal and Bangladesh. We find the highest fog occurrences in the low333 lying Terai region in the bordering areas of northern India and southern Nepal, which runs 334 parallel to the lower Himalayan ranges, as consistently indicated in both the daytime and nighttime satellite derived data. We anticipate the high-resolution long-term fog data record derived from satellite observations in this study addresses a gap in the present understanding of

337 the winter fog characteristics focused over the IGP, especially from a long-term spatial-temporal 338 perspective. The satellite-based detection framework as discussed here can also be used to 
339 routinely map and quantify fog occurrences or help advance existing approaches towards

340 developing a robust fog monitoring tool specifically in the IGP as well as in other geographies

341 around the world that are subject to fog formation.

342

343 Acknowledgements

344 MODIS Level-1b and Level-2 used in this study were downloaded from NASA's LAADS

345 DAAC https://ladsweb.modaps.eosdis.nasa.gov/. We thank Sarwar Rizvi, IIT Bombay for

346 providing the initial analysis of fog remote sensing for this work and thank Piyush Patel,

347 JPL/CalTech for helpful discussions regarding meteorological analysis related to fog variability.

348 R.G. is thankful to Center of Studies in Resources Engineering, IIT Bombay for providing

349 computational support towards the initial analysis for this work.

350 Declaration of Competing Interest

351 The authors have no competing interests to declare. 
Figures
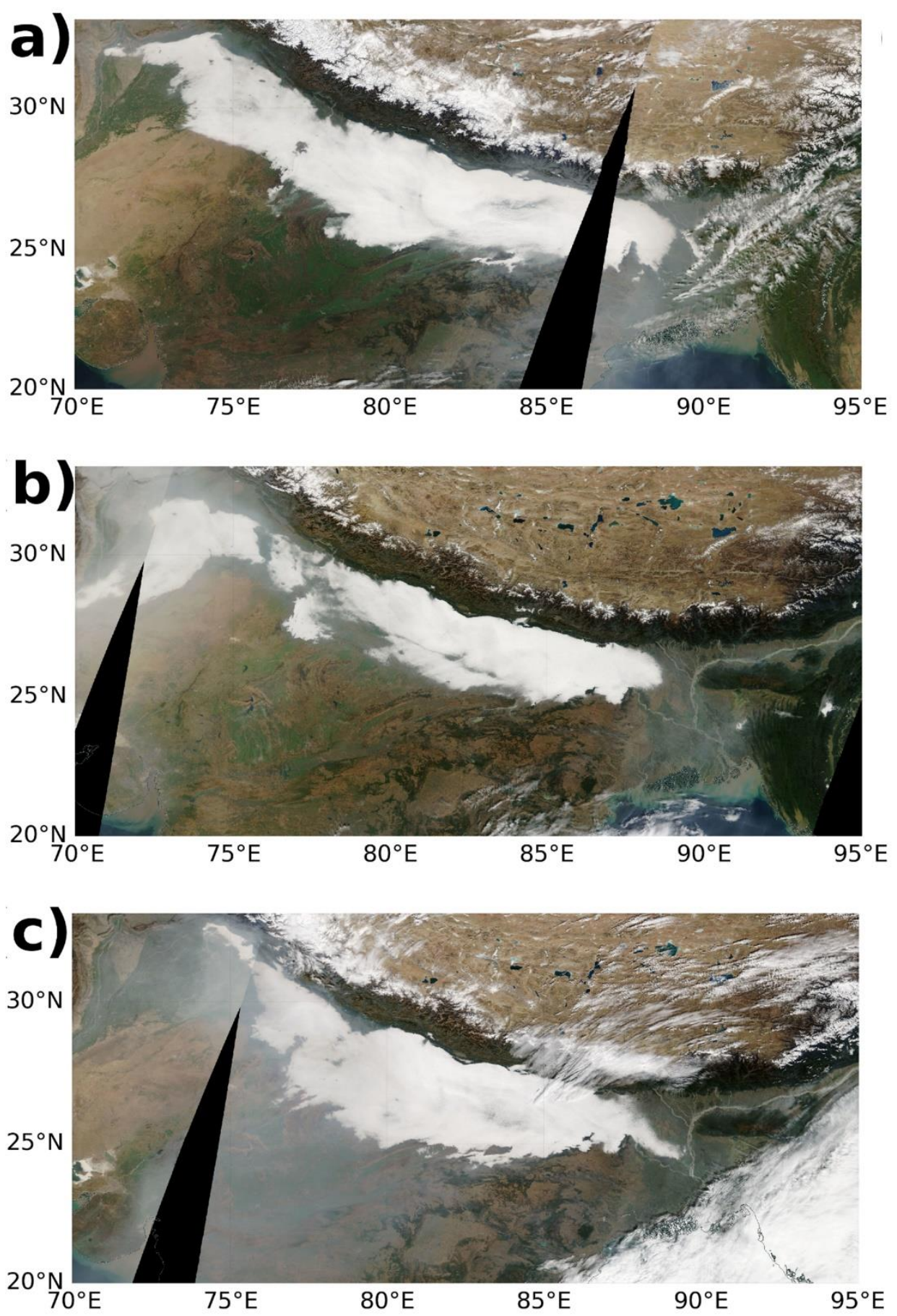

363 Figure 1: True color Terra/MODIS imagery of fog cover over the Indo-Gangetic Plains on (a) 36430 January 2014, (b) 11 December 2016 and (c) 1 January 2018. 

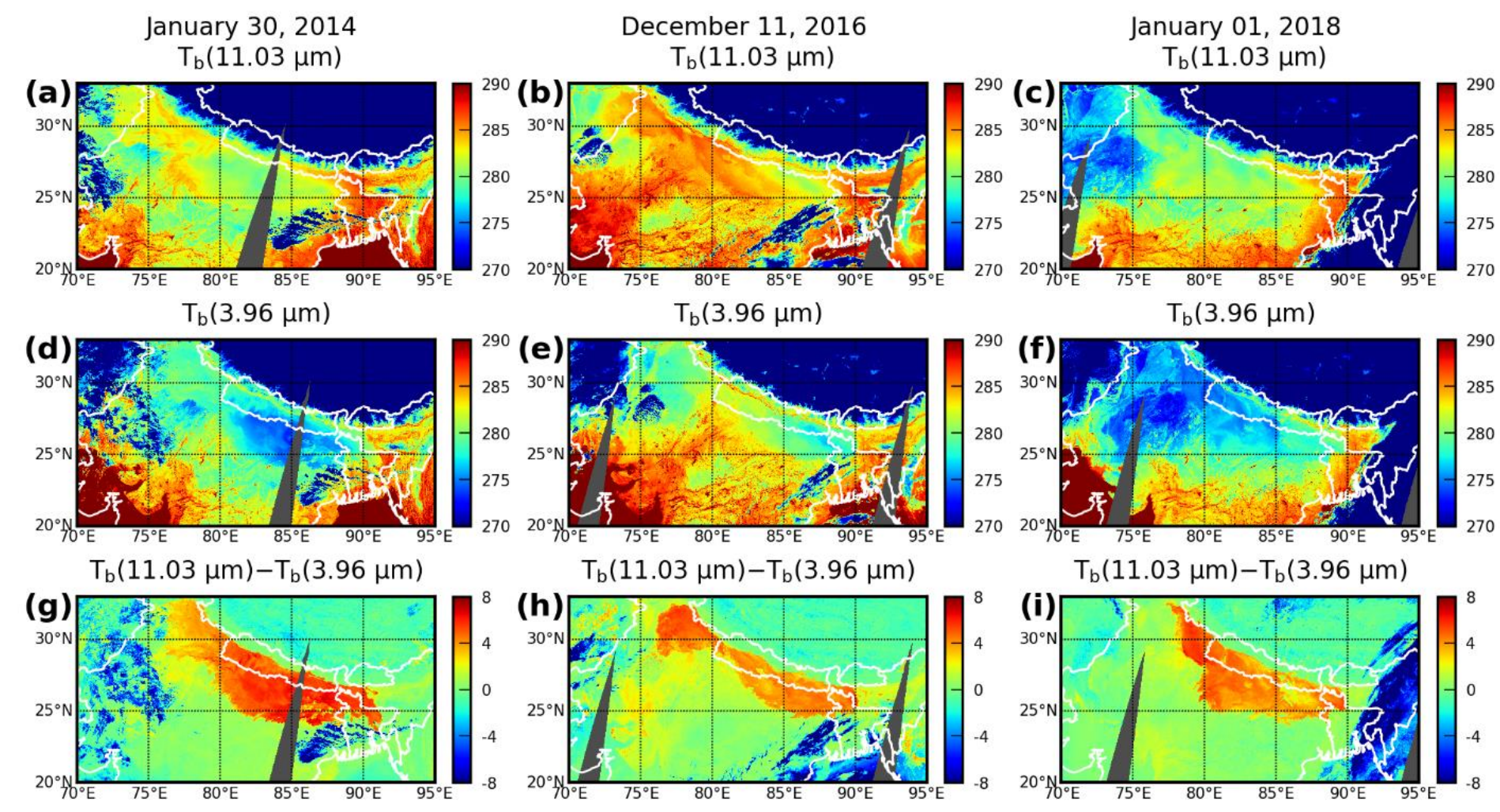

366 Figure 2: Brightness temperature $\left(\mathrm{T}_{\mathrm{b}}\right)$ computed using Aqua/MODIS band $22(3.9 \mu \mathrm{m})$ for (a)

36730 January 2014, (b) 11 December 2016 and (c) 1 January 2018; and band 31 (11.02 $\mu \mathrm{m}$ ) for (d)

36830 January 2011, (e) 11 December 2016 and (f) 1 January 2018 and brightness temperature

369 difference between band 31 and band 22 for (g) 30 January 2014 (h) 11 December 2016 (i) and

3701 January 2018 from Aqua/MODIS observations focused over the Indo-Gangetic Plains bounded

371 by $70^{\circ}-95^{\circ} \mathrm{E}$ longitudes and $20^{\circ}-33^{\circ} \mathrm{N}$ latitudes. 

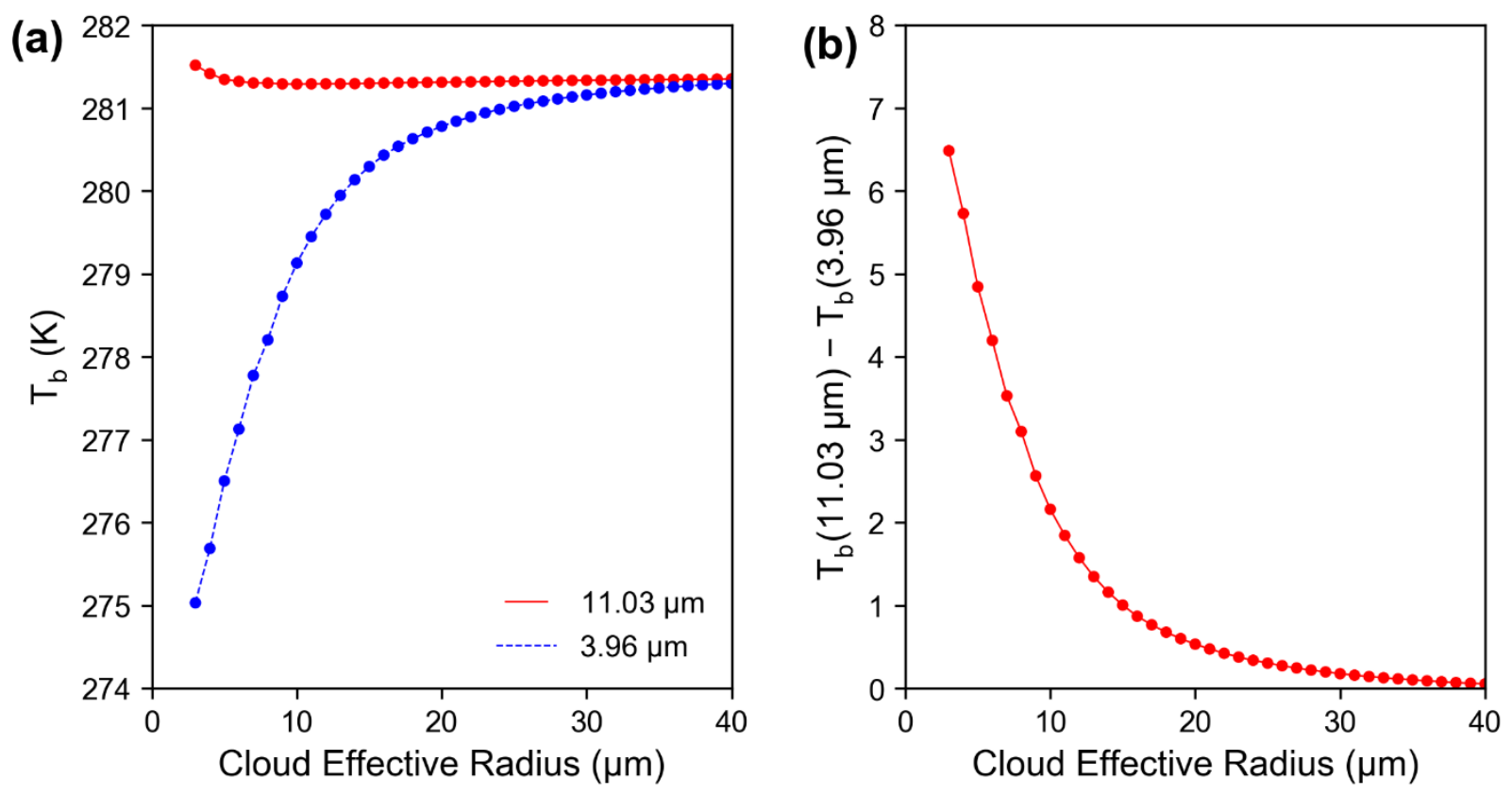

375 Figure 3: (a) Variation in the brightness temperature with cloud effective radius at $3.96 \mu \mathrm{m}$ for 376 and $11.03 \mu \mathrm{m}$ computed from radiative transfer simulations at sensor zenith angle of $20^{\circ}$ and 377 cloud optical thickness of 30. (b) Variation of brightness temperature difference (BTD) (3.96 $\mu \mathrm{m}$ 378 and $11.03 \mu \mathrm{m}$ ) with cloud effective radius.

379

380

381

382 

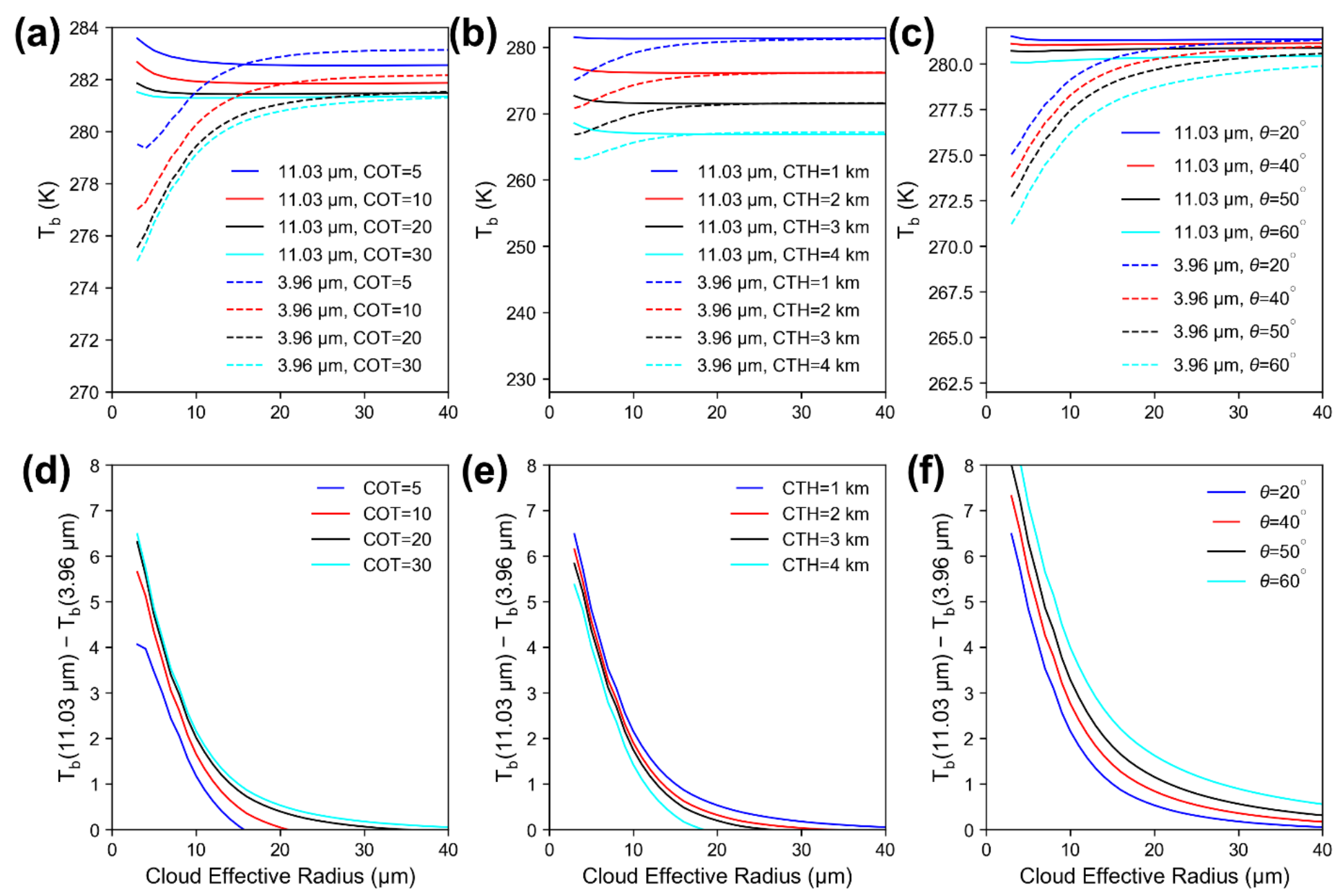

384 Figure 4: (a) Variation of brightness temperature $\left(T_{b}\right)$ with cloud effective radius (CER) and 385 cloud optical thickness (COT) at $3.96 \mu \mathrm{m}$ and $11.03 \mu \mathrm{m}$ based on radiative transfer model

386 computations at sensor zenith angle, $\theta=20^{\circ}$ and at cloud top height $(\mathrm{CTH})=1 \mathrm{~km}$. (b)

387 Variation in $T_{b}(11.03 \mu \mathrm{m})$ and $T_{b}(3.96 \mu \mathrm{m})$ with CER and CTH at COT $=30$ and $\theta=20^{\circ}$. (c)

388 Variation of $T_{b}(11.03 \mu \mathrm{m})-T_{b}(3.96 \mu \mathrm{m})$ with CER and $\theta$ at COT $=30$ and $\mathrm{CTH}=1 \mathrm{~km}$. (d)

389 Variation of brightness temperature difference, $T_{b}(11.03 \mu \mathrm{m})-T_{b}(3.96 \mu \mathrm{m})$ with CER and

$390 \mathrm{COT}$ at $3.96 \mu \mathrm{m}$ and $11.03 \mu \mathrm{m}$ at $\theta=20^{\circ}$ and at $\mathrm{CTH}=1 \mathrm{~km}$. (e) Variation in the

$391 T_{b}(11.03 \mu \mathrm{m})-T_{b}(3.96 \mu \mathrm{m})$ with CER and CTH at COT $=30$ and $\theta=20^{\circ}$. (f) Variation in

$392 T_{b}(11.03 \mu \mathrm{m})-T_{b}(3.96 \mu \mathrm{m})$ with CER and $\theta$ at $\mathrm{COT}=30$ and $\mathrm{CTH}=1 \mathrm{~km}$. 

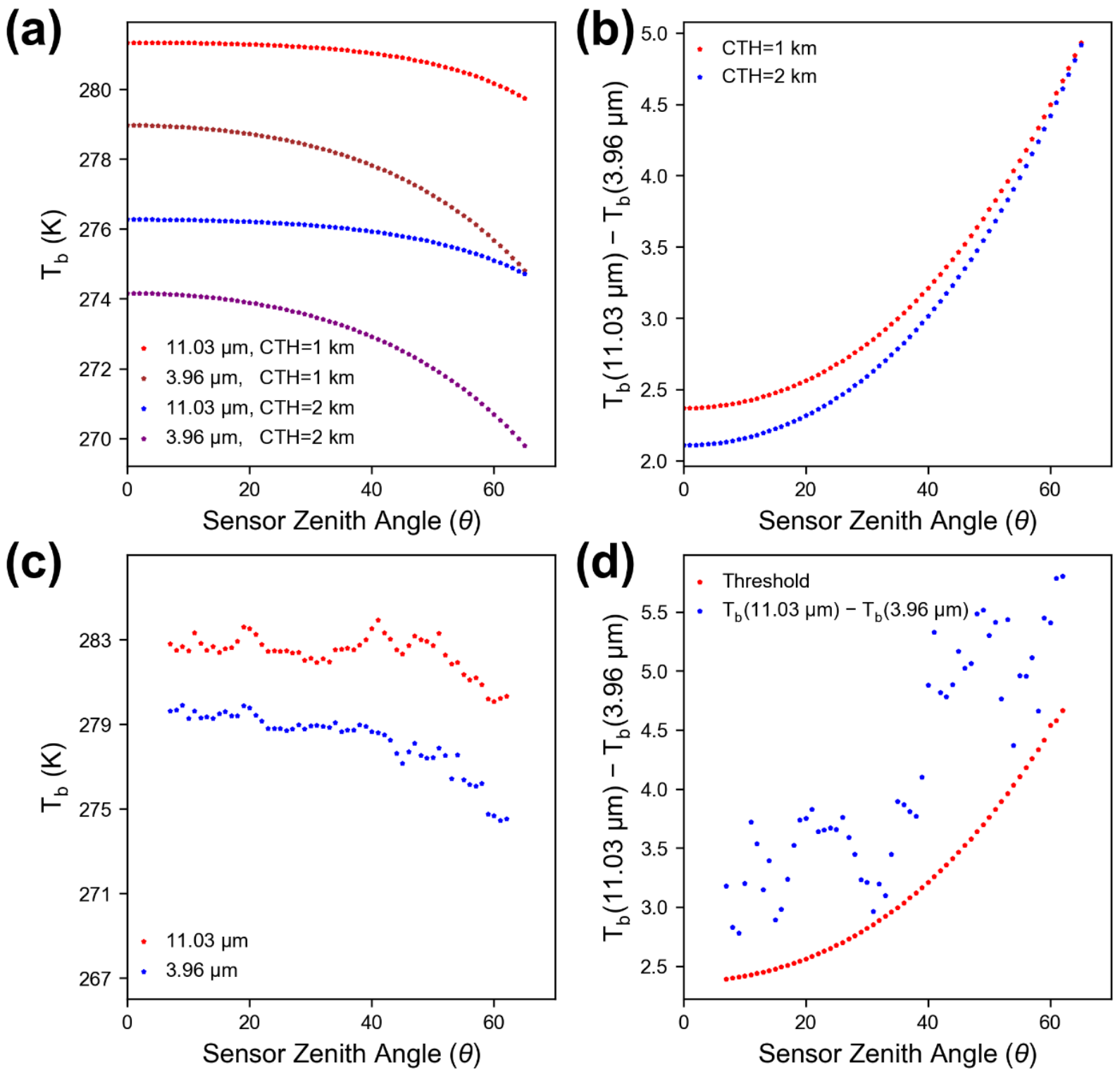

Figure 5: (a) Variation in the brightness temperature $\left(T_{b}\right)$ with sensor zenith angle $(\theta)$ and cloud top height $(\mathrm{CTH})$ at $3.96 \mu \mathrm{m}$ and $11.03 \mu \mathrm{m}$ and at cloud effective radius (CER $=9 \mu \mathrm{m}$ ) simulated using a radiative transfer model. (b) Variation of brightness temperature difference ( $\left.T_{b}\right)(11.03 \mu \mathrm{m}$ and $3.96 \mu \mathrm{m})$ with $\theta$ and CTH. (c) Variation in $T_{b}$ with $\theta$ at $3.96 \mu \mathrm{m}$ and 11.03 $\mu \mathrm{m}$ for the fog-covered pixels along a transect (the transect is a straight line joining two points, point 1 (latitude $=32.5^{\circ} \mathrm{N}$, longitude $=73.5^{\circ} \mathrm{E}$ ) and point 2 (latitude $=24.5^{\circ} \mathrm{N}$, longitude $=85.5^{\circ} \mathrm{E}$ ) across the IGP for 30 January 2014. (d) Variation of $T_{b}(11.03 \mu \mathrm{m})-T_{b}(3.96 \mu \mathrm{m})$ and difference threshold with $\theta$ and $\mathrm{CTH}$. The red dots show the threshold computed from a radiative transfer model as a function of $\theta$ and CTH. The green dots show the brightness temperature difference along the transect for the 30 January 2014. 

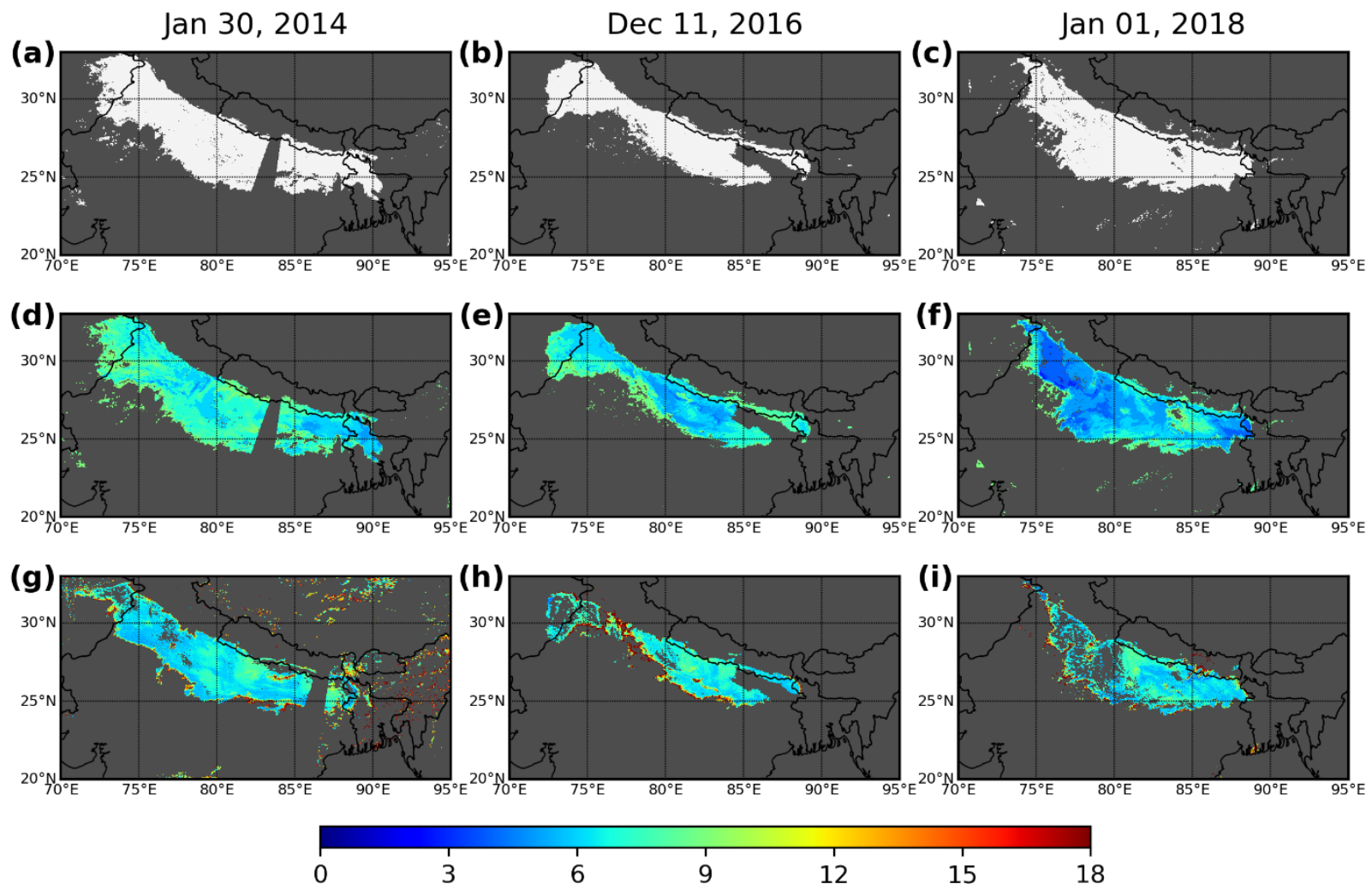

6

Figure 6: (a) Fog over the IGP observed using the nighttime fog detection algorithm for 30

406 January 2014, (b) 11 December 2016, and (c) 1 January 2018 (d) Simulated nighttime CER (unit $407-\mu \mathrm{m}$ ) over the Indo-Gangetic Plains for 30 January 2014, (e) 11 December 2016 and (f) 1 408 January 2018 (g) The CER retrievals (unit - $\mu \mathrm{m}$ )from Terra/MODIS for daytime for January 30, 409 2014, (h) 11 December, 2016 and (i) 1 January 2018. 


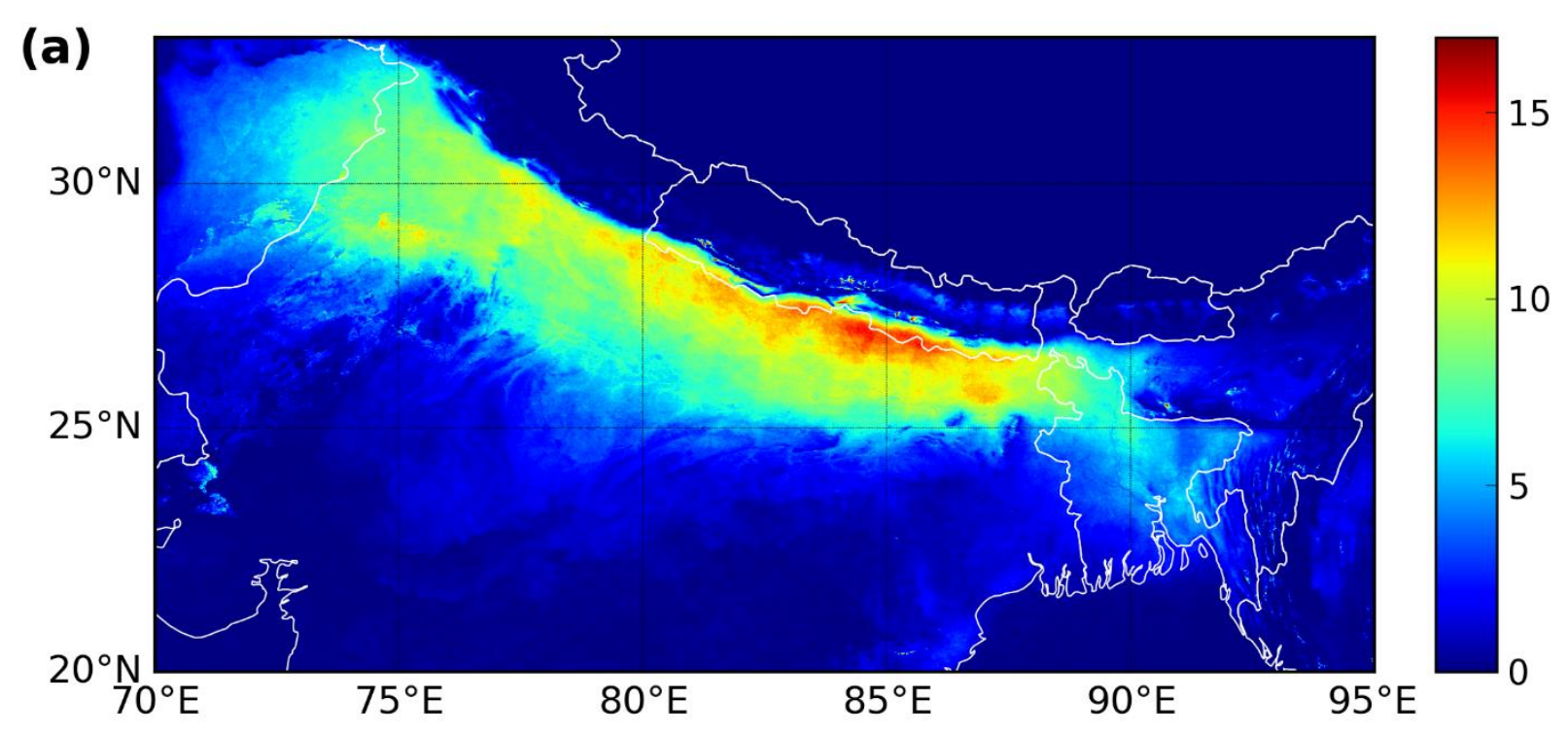

(b)

411 Figure 7: (a) Mean seasonal fog frequency (December-January) computed using the nighttime 412 fog detection algorithm using daily Aqua/MODIS observations ( 1:30 am local-time), over the 413 Indo-Gangetic Plains for the period 2002-20. Colorbar indicates number of days fog was 414 detected during December-January. (b) Mean seasonal fog frequency (December-January)

415 computed using the daytime fog detection analysis using Terra/MODIS observations ( 10:30 am 416 local-time), for the period 2002-20. The largest fog frequency is found in the bordering areas of 417 India and Nepal, along the Terai region, south of the Himalayan foothills. 


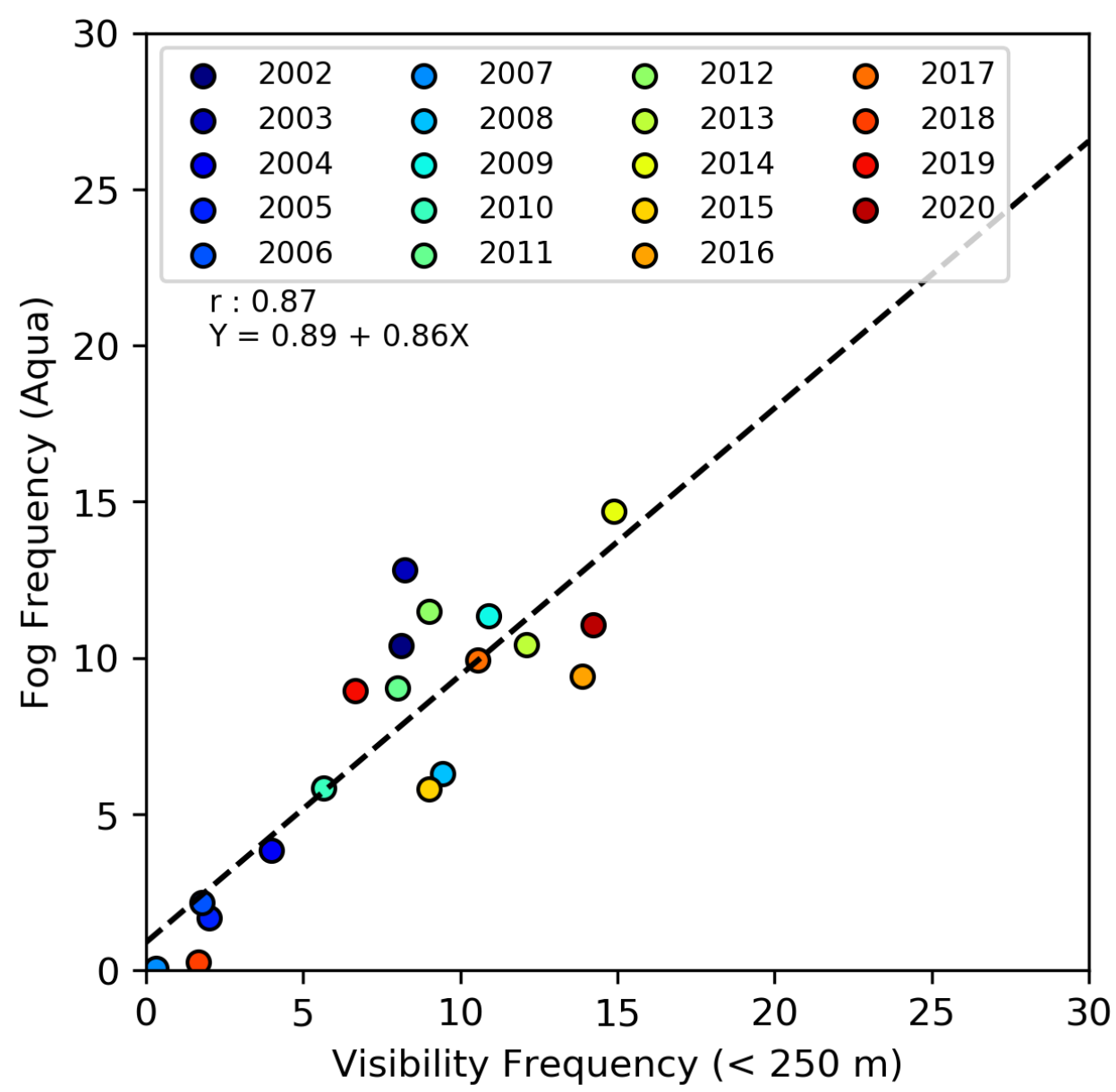

421

422 Figure 8: Intercomparison of seasonal fog frequency, derived using nighttime Aqua/MODIS

423 observations for the period 2002-2020 for the winter months of December-January, with the poor

424 visibility frequency (visibility $<250 \mathrm{~m}$ ) computed from ground meteorological data.

425

426 


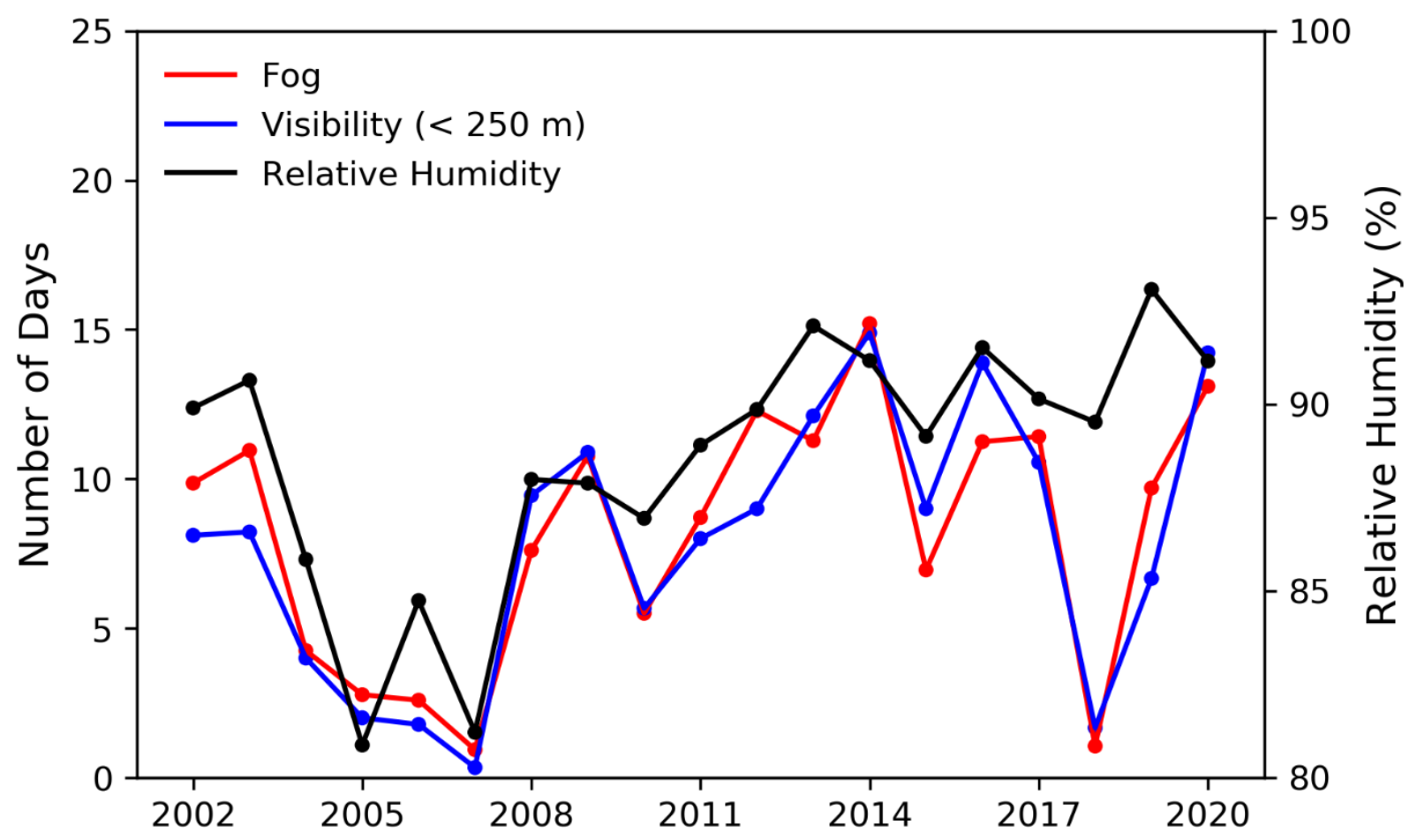

427

428

429

430

431

432

433

434

435

436

437

438

439

440

441

442

443

.

Figure 9: Interannual variations of fog frequency (red) derived using Aqua/MODIS observations for the winter months of December-January for the period 2002-2020, poor visibility frequency (visibility $<250 \mathrm{~m}$ ) is shown in blue and relative humidity $(\%)$ from ground meteorological observations in the Indo-Gangetic Plains.

\section{2}

3

4

5

6

\section{7}

38

39

43




\section{References}

445 Agarwal, A., Mangal, A., Satsangi, A., Lakhani, A., Maharaj Kumari, K., 2017.

446 Characterization, sources and health risk analysis of PM2. 5 bound metals during foggy and non-

447 foggy days in sub-urban atmosphere of Agra. Atmospheric Research 197, 121-131.

448 Ahmed, R., Dey, S., Mohan, M., 2015. A study to improve night time fog detection in the Indo-

449 Gangetic basin using satellite data and to investigate the connection to aerosols. Meteorological

450 Applications 22, 689-693.

451 Ahn, M.H., Sohn, E.H., Hwang, B.J., 2003. A new algorithm for sea fog/stratus detection using 452 GMS-5 IR data. Advances in Atmospheric Sciences 20, 899-913.

453 Banerjee, S., Padmakumari, B., 2020. Spatiotemporal variability and evolution of day and night 454 winter fog over the Indo Gangetic Basin using INSAT-3D and comparison with surface visibility 455 and aerosol optical depth. Science of The Total Environment 745, 140962.

456 Bendix, J., Thies, B., Cermak, J., Nau, T., 01 Dec. 2005. Ground fog detection from space based 457 on MODIS daytime data-a feasibility study. Weather and Forecasting 20, 989 - 1005.

458 Bhatta, G.D., Aggarwal, P.K., Kristjanson, P., Shrivastava, A.K., 2016. Climatic and non459 climatic factors influencing changing agricultural practices across different rainfall regimes in 460 South Asia. Current Science 110, 1272-1281.

461 Cermak, J., Bendix, J., 2007. Dynamical nighttime fog/low stratus detection based on Meteosat 462 SEVIRI data: A feasibility study. Pure and Applied Geophysics 164, 1179-1192.

463 Chaurasia, S., Sathiyamoorthy, V., Shukla, B., Simon, B., Joshi, P., Pal, P., 2011. Night time fog 464 detection using MODIS data over Northern India. Meteorological Applications 18, 483 - 494.

465 Decesari, S., Sowlat, M. H., Hasheminassab, S., Sandrini, S., Gilardoni, S., Facchini, M. C., ... 466 Sioutas, C. (2017). Enhanced toxicity of aerosol in fog conditions in the Po Valley, Italy.

467 Atmospheric Chemistry and Physics, 17(12), 7721- 7731.

468 Dey, S., 2018. On the theoretical aspects of improved fog detection and prediction in India.

469 Atmospheric Research 202, 77-80.

470 Ellrod, G.P., 1995. Advances in the detection and analysis of fog at night using GOES

471 multispectral infrared imagery. Weather and Forecasting 10, 606-619.

472 Eyre, J., Brownscombe, J., Allam, R., 1984. Detection of fog at night using Advanced Very High 473 Resolution Radiometer (AVHRR) imagery. Meteorological Magazine 113, 266-271.

474 Gautam, R., Hsu, N.C., Kafatos, M., Tsay, S.C., 2007. Influences of winter haze on fog/low 475 cloud over the Indo-Gangetic plains. Journal of Geophysical Research: Atmospheres 112.

476 Gautam, R., 2014. Challenges in Early Warning of the Persistent and Widespread Winter Fog 477 over the Indo-Gangetic Plains: A Satellite Perspective. Springer Netherlands, Dordrecht. pp. 5147861. 
Gautam, R., Singh, M.K., 2018. Urban heat island over Delhi punches holes in widespread fog in the Indo-Gangetic plains. Geophysical Research Letters 45, 1114-1121.

Ghude, S., Bhat, G., Prabha, T., Jenamani, R., Chate, D., Safai, P., Karipot, A., Konwar, M., Pithani, P., Sinha, V., Pasumarti, R., Dixit, S., Tiwari, S., Todekar, K., Varpe, S., Srivastava, A., Bisht, D., Murugavel, P., Ali, K., Rajeevan, M., 2017. Winter fog experiment over the IndoGangetic plains of India. Current Science 112, 767.

Gultepe, I., Tardif, R., Michaelides, S.C., Cermak, J., Bott, A., Bendix, J., Müller, M.D., Pagowski, M., Hansen, B., Ellrod, G. and Jacobs, W., 2007. Fog research: A review of past achievements and future perspectives. Pure and applied geophysics 164(6), 1121-1159.

Gupta, S.K., Elumalai, S.P., 2018. Adverse impacts of fog events during winter on fine particulate matter, CO and VOCs: a case study of a highway near Dhanbad, India. Weather 73, 396-402.

Hameed, S., Mirza, M.I., Ghauri, B.M., Siddiqui, Z.R., Javed, R., Khan, A.R., Rattigan, O.V., Qureshi, S., Husain, L., 2000. On the widespread winter fog in Northeastern Pakistan and India. Geophysical Research Letters 27, 1891-1894.

Hunt, G.E., 1973. Radiative properties of terrestrial clouds at visible and infra-red thermal window wavelengths. Quarterly Journal of the Royal Meteorological Society 99, 346-369.

Jenamani, R., 2007. Alarming rise in fog and pollution causing a fall in maximum temperature over Delhi. Current Science 93.

Lee, T.F., Turk, F.J., Richardson, K., 1997. Stratus and fog products using goes-89 3.9- $\mu \mathrm{m}$ data.Weather and Forecasting 12, $664-677$.

Li, H., Wang, Q., Shao, M., Wang, J., Wang, C., Sun, Y., Qian, X., Wu, H., Yang, M., Li, F., 2016. Fractionation of airborne particulate-bound elements in haze-fog episode and associated health risks in a megacity of southeast China. Environmental Pollution 208, 655-662.

Pan, X., Chin, M., Gautam, R., Bian, H., Kim, D., Colarco, P. R., ... \& Bellouin, N., 2015. A multi-model evaluation of aerosols over South Asia: common problems and possible causes. Atmospheric Chemistry and Physics 15, 5903-5928.

Pasricha, P.K., Gera, B.S., Shastri, S., Maini, H.K., John, T., Ghosh, A.B., Tiwari, M.K., Garg, S.C., 2003. Role of the water vapour green-house effect in the forecasting of fog occurrence. Boundary-Layer Meteorology 107, 469-482.

Platnick, S., Meyer, K.G., King, M.D., Wind, G., Amarasinghe, N., Marchant, B., Arnold, G.T., Zhang, Z., Hubanks, P.A., Holz, R.E., Yang, P., Ridgway, W.L., Riedi, J., 2016. The MODIS cloud optical and microphysical products: Collection 6 updates and examples from terra and aqua. IEEE Transactions on Geoscience and Remote Sensing 55, 502-525.

Ricchiazzi, P., Yang, S., Gautier, C., Sowle, D., 01 Oct. 1998. SBDART: A research and teaching software tool for plane-parallel radiative transfer in the earth's atmosphere. Bulletin of the American Meteorological Society 79, $2101-2114$. 
516 Saikawa, E., Panday, A., Kang, S., Gautam, R., Zusman, E., Cong, Z., Somanathan, E., 517 Adhikary, B., 2019. Air Pollution in the Hindu Kush Himalaya. Springer International

518 Publishing, Cham. pp. 339-387.

519 Turner, J., Allam, R., Maine, D., 1986. A case-study of the detection of fog at night using

520 channels 3 and 4 on the Advanced Very High-Resolution Radiometer (AVHRR). Meteorological

521 Magazine 115, 285-290.

522 Venkataraman, C., Brauer, M., Tibrewal, K., Sadavarte, P., Ma, Q., Cohen, A., Chaliyakunnel, 523 S., Frostad, J., Klimont, Z., Martin, R.V., Millet, D.B., Philip, S., Walker, K., Wang, S., 2018.

524 Source influence on emission pathways and ambient PM 2.5 pollution over India (2015-2050).

525 Atmospheric Chemistry and Physics 18, 8017-8039.

526 Wilcox, E. M. (2017). Multi-spectral remote sensing of sea fog with simultaneous passive

527 infrared and microwave sensors. In Marine Fog: Challenges and Advancements in Observations,

528 Modeling, and Forecasting. Springer, Cham 511-526.

529 Zhang, Y.J., Holbrook, N.M., Cao, K.F., 2014. Seasonal dynamics in photosynthesis of woody

530 plants at the northern limit of Asian tropics: potential role of fog in maintaining tropical

531 rainforests and agriculture in Southwest China. Tree Physiology 34, 1069-1078.

532

533

534

535

536

537

538

539

540

541

542

543

544

545

546

547 
Developing a long-term high-resolution winter fog climatology over south Asia

\section{using satellite observations from 2002 to 2020}

551

552

553

554

555

556

557

558

559

560

561

562

563

564

565

566

567

568

569

570

571

572

573

\section{Manoj K. Singh ${ }^{a}$ and Ritesh Gautam ${ }^{b^{*}}$}

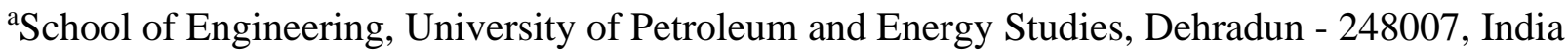

${ }^{\mathrm{b}}$ Environmental Defense Fund, Washington, DC 20009, USA

*Corresponding author - rgautam@edf.org

\section{S1. Estimation of nighttime CER}

We created a lookup table for brightness temperature at $11.03 \mu \mathrm{m}$ and $3.96 \mu \mathrm{m}$ and their difference for characterizing fog/low clouds as a function of $\theta, r_{c}, h_{c}$ and COT. Since the MODIS cloud product does not include retrievals of cloud effective radius during nighttime observations, the microphysics information is presently lacking for fog/low cloud in satellite data. We provide here an estimation of the $r_{c}$ for fog-detected pixels. For instance for each value of $t_{c}$ assumed between 25-35, we simulated the effective radius which was used to compute a mean $r_{c}$ along with the uncertainty based on $+/-1$ standard deviation (SD). Fig. 6 and Fig. S2a, S2b and S2c (in supporting information) show the simulated nighttime $r_{c}$ at foggy pixels for 30 January 2014, 11 December 2016 and 1 January 2018, respectively. In all three cases, the maximum SD of the retrieved $r_{c}$ is 0.5 ; therefore, the $r_{c}$ at each pixel is similar for all values of $t_{c}$ between 25-35. Since nighttime cloud effective radii are not available, the simulated $r_{c}$ are compared with MODIS daytime cloud effective radius, as a way of intercomparison but not validation. The Figures S2d, S2e and S2f show the MODIS daytime cloud effective radius for 30 January 2014, 11 December 2016 and 1 January 2018, respectively. The figures suggest that the CER is consistently less than $9 \mu \mathrm{m}$ in both nighttime and daytime analysis where the histogram distributions are generally found to be consistent. 


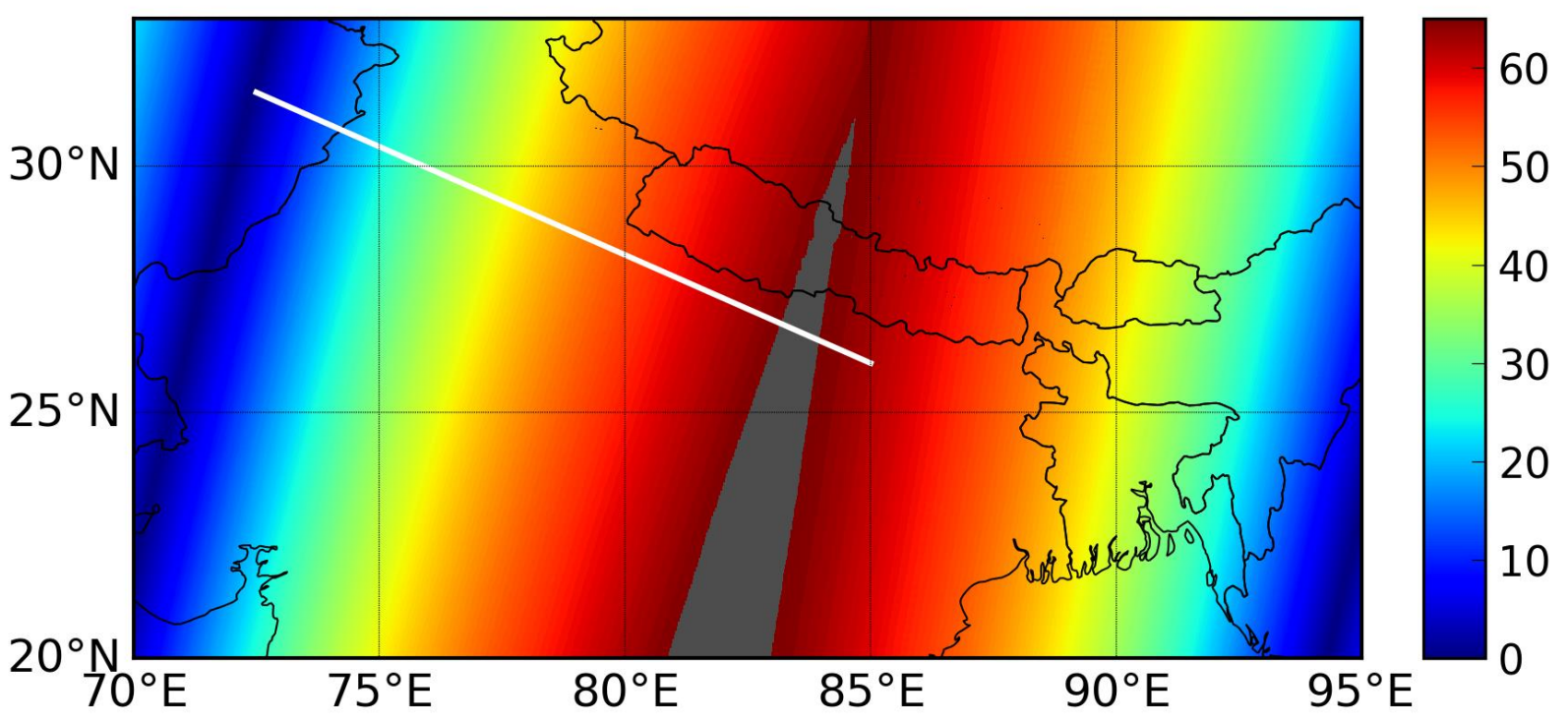

Figure S1: A transect (in white color) in the IGP along which the plots in main Fig. 5c and Fig. $5 \mathrm{~d}$ are presented. For reference, in the background MODIS sensor zenith angle is shown (with its colorbar indicating angles in degrees) on 30 January 2014. 
Jan 30, 2014
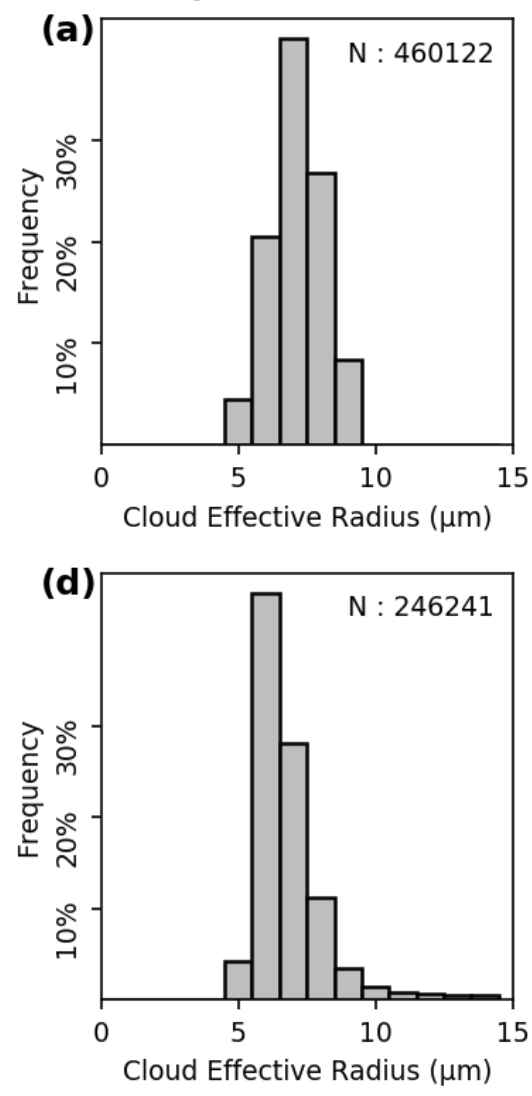

Dec 11, 2016
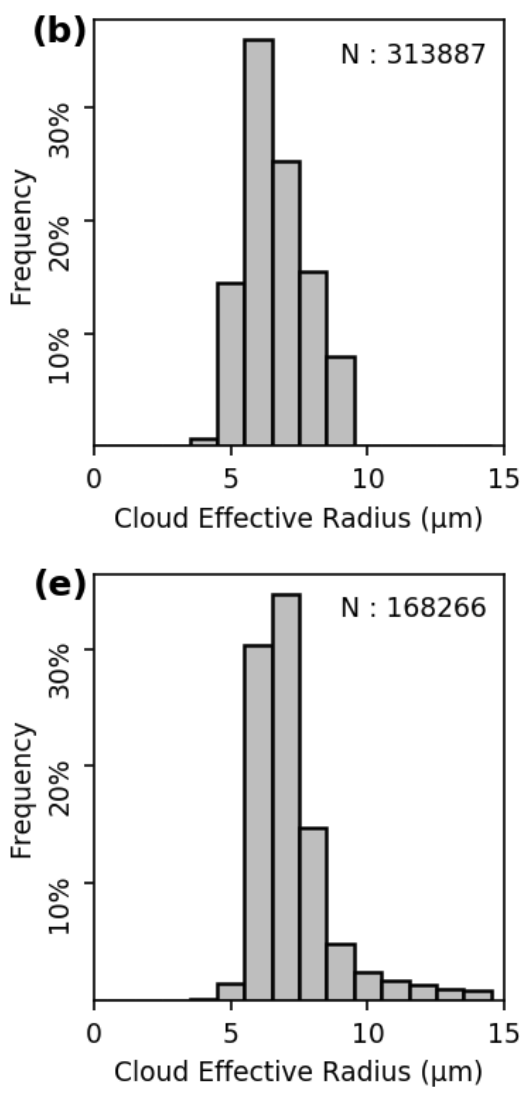

Jan 1, 2018
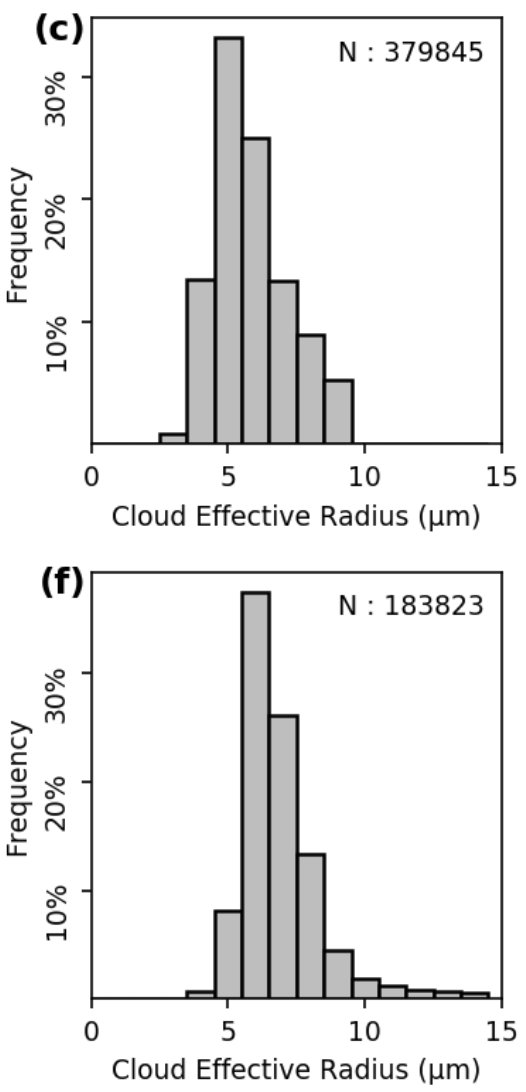

Figure S2: Histogram of the radiative transfer simulated nighttime CER over the IGP for (a) 30 January 2014, (b) 11 December 2016 and (c) 1 January 2018. Histograms of the CER retrievals 598 from the MODIS (Terra) for daytime for (d) January 30, 2014, (e) 11 December, 2016 and (f) 1 599 January 2018 are also shown.

600

601

602

603

604

605 
607 Table S1: City names and coordinates of the nine ground stations distributed across IGP.

\begin{tabular}{|l|l|l|}
\hline Name & Latitude & Longitude \\
\hline Amritsar & $31.710^{\circ} \mathrm{N}$ & $74.797^{\circ} \mathrm{E}$ \\
\hline Bareilly & $28.422^{\circ} \mathrm{N}$ & $79.451^{\circ} \mathrm{E}$ \\
\hline Gaya & $24.744^{\circ} \mathrm{N}$ & $84.951^{\circ} \mathrm{E}$ \\
\hline Gorakhpur & $26.740^{\circ} \mathrm{N}$ & $83.450^{\circ} \mathrm{E}$ \\
\hline Hissar & $29.179^{\circ} \mathrm{N}$ & $75.755^{\circ} \mathrm{E}$ \\
\hline IGI & $28.567^{\circ} \mathrm{N}$ & $77.103^{\circ} \mathrm{E}$ \\
\hline Lucknow & $26.761^{\circ} \mathrm{N}$ & $80.889^{\circ} \mathrm{E}$ \\
\hline Patna & $25.591^{\circ} \mathrm{N}$ & $85.088^{\circ} \mathrm{E}$ \\
\hline Safdarjung & $28.585^{\circ} \mathrm{N}$ & $77.206^{\circ} \mathrm{E}$ \\
\hline
\end{tabular}

608

609

610

611 